\title{
Brincando de roda com bebês em uma instituição de Educação Infantil
}

\section{Singing games with infants in an Early Childhood Education Center}

\author{
Elenice de Brito Teixeira Silva* \\ Vanessa Ferraz Almeida Neves**
}

\begin{abstract}
RESUMO
O presente artigo discute a trajetória da brincadeira de roda em um grupo de bebês ${ }^{1}$ em uma Escola Municipal de Educação Infantil em Belo Horizonte, entre fevereiro de 2017 e julho de 2018. Com base nos princípios da Etnografia em Educação e da Psicologia Histórico-cultural, temos acompanhado esse grupo desde seu ingresso na instituição em 2017, quando os bebês tinham entre 7 e 10 meses de idade. Tomamos as brincadeiras de roda em sua dupla temporalidade, tanto como brincadeira tradicional quanto em sua dimensão de (re)apropriação pelo grupo investigado. A atividade de brincar, entendida como uma vivência da criança em seu grupo social, integra emoção, cognição, linguagem, corpo, cultura. Nossas análises focalizam a trajetória da brincadeira no grupo e apontam para ela como enlaçamento do outro, em que crianças e adultos ampliam as possibilidades dessa atividade $\mathrm{e}$, consequentemente, de desenvolvimento cultural dos participantes.
\end{abstract}

Palavras-chave: Bebês. Brincadeira de roda. Psicologia Histórico-cultural.

* Universidade do Estado da Bahia. Departamento de Educação. Guanambi, Bahia, Brasil. E-mail: elenteixeira@yahoo.com.br. http://orcid.org/0000-0001-8145-6664.

${ }^{* *}$ Universidade Federal de Minas Gerais. Faculdade de Educação. Belo Horizonte, Minas Gerais, Brasil. E-mail: vfaneves@gmail.com. http://orcid.org/0000-0003-4094-3639.

1 Neste texto, estamos denominando bebês todas as crianças de 0 a 18 meses. A partir desse recorte etário, utilizamos apenas o termo "crianças" em consonância com a nomenclatura e divisão de grupos por faixa etária adotadas pela Base Nacional Curricular Comum (Lei 13.415/2017). 


\begin{abstract}
This article discusses the trajectory of singing games in a group of infants in an Early Childhood Education Center in the city of Belo Horizonte, Brazil, between February of 2017 and July of 2018. Based on the principles of Ethnography in Education and Cultural-historical Psychology, we have been following this group since 2017 when they were 7 to 10 months old. We analyze the singing games in their double temporality, both its tradition as a game and its dimension of (re)appropriation by the investigated group. The activity of playing understood as a lived experience of the child in his/ her social group integrates emotion, cognition, language, body, and culture. Our analyses focus on the trajectory of this play in the group and point to it as a social bond in which children and adults expand the possibilities of this activity and, therefore, the cultural development of the participants.
\end{abstract}

Keywords: Infants. Play. Cultural-historical psychology.

\title{
Introdução
}

É início da tarde e as crianças de uma Escola Municipal de Educação Infantil (EMEI) em Belo Horizonte estão ouvindo uma história contada pela professora. São crianças com idade entre 18 e 24 meses de uma turma de tempo integral. Há nove crianças escutando uma história no tapete, enquanto duas meninas tentam pegar água que está sobre a pia da sala. Ao terminar a história, a professora convida a turma para brincar de abraçar. Simone deixa a pia e se aproxima da professora. Ao invés de participar da brincadeira que a professora está fazendo com algumas crianças, Simone segura a mão de Marina e as duas seguram a mão de outra colega, afastando-se do grupo. As três meninas começam a cantar miau e Marina se abaixa. Esse é o começo de um evento que se expande em tentativas de construção de sentidos por meio de gestos, palavras e movimentos, por meio dos quais as crianças criam oportunidades para brincar de roda. Há dois planos vivenciais nesse momento: um criado pela professora em torno da brincadeira de abraçar, que abrange um maior número de crianças; e outro criado por Simone e Marina para construírem uma brincadeira de roda. Mas como isso aconteceu? Quem participou da brincadeira? Como começaram, sustentaram e finalizaram a brincadeira? Enfim, o que há nesse evento que evidencia a construção de uma perspectiva compartilhada da brincadeira de roda na trajetória do grupo? 
Essas questões constituem objetivos de uma pesquisa ${ }^{2}$ que busca compreender o processo de construção do contexto de brincadeiras pelas crianças de uma EMEI, por meio de uma abordagem etnográfica. Partimos do pressuposto de que as oportunidades de brincar são vivenciadas com outras crianças e adultos, com os espaços e artefatos culturais, e que uma observação prolongada evidenciará princípios que orientam continuidades e mudanças nessa construção. Entendemos, pois, que os contextos existem como uma relação entre eventos e campos de ação (REX; GREEN; DIXON, 1998) em que as crianças estão situadas, e, nessa relação, as pessoas também são contextos umas para as outras (ERICKSON; SCHULTZ, 2002). Portanto, uma perspectiva dialética da brincadeira busca evidenciar as relações estabelecidas por meio das quais as crianças e professoras brincam e (re)produzem brincadeiras, modificando os contextos e as próprias brincadeiras, mesmo as mais tradicionais como a de roda.

As produções acadêmicas têm enfatizado as interações e brincadeiras entre crianças maiores de 4 anos (por exemplo, BORBA, 2005) e há alguns estudos com foco nos bebês, 0 a 18 meses (por exemplo, PEDROSA; CARVALHO, 1995). Entretanto, as brincadeiras entre crianças de 18 meses e 3 anos ocupam um lugar tangencial no conjunto das produções. Em geral, os estudos que têm como foco as crianças desse agrupamento tendem a classificar as brincadeiras observadas e concluírem pelo predomínio da brincadeira com objetos (LORDELO; CARVALHO, 2006), bem como enfatizam que a apropriação da linguagem verbal e a conquista da "marcha" são importantes na construção das interações e nas atividades das crianças.

Também podemos dizer que há o predomínio da abordagem da brincadeira dos bebês em correntes da Psicologia (por exemplo, LORDELO; CARVALHO, 2006), das crianças maiores, na Sociologia da Infância (BORBA, 2005), com exceção do trabalho de Ângela Coutinho (2010) sobre a ação social dos bebês a partir de fundamentos desta área de estudos. Em que pesem as distinções nessas abordagens, os estudos convergem na busca pela compreensão da natureza do brincar ou no que acontece quando crianças brincam juntas em contextos coletivos. Em alguns estudos interdisciplinares (por exemplo, PRADO, 1998), há um questionamento sobre as categorias utilizadas para definir o que seja ou não brincadeira e que evidenciam a insuficiência da abordagem hipotético-dedutiva para analisar essa atividade.

2 Trata-se de um estudo inserido em um programa de pesquisa que acompanha uma turma de bebês ao longo da sua trajetória na Educação Infantil. As autoras agradecem ao apoio financeiro do Conselho Nacional de Desenvolvimento Científico e Tecnológico (CNPQ), da Coordenação de Aperfeiçoamento de Pessoal de Nível Superior (CAPES) e do Programa de Apoio à Capacitação Docente e de técnicos administrativos da Universidade do Estado da Bahia (PAC-DT/UNEB). 
Alguns trabalhos europeus (STAMBACK; VERBA, 1986; MUSATTI; PANNI, 1981) documentaram atividades comuns entre bebês de 6 meses a 3 anos em creches francesas e italianas, descrevendo a ritualização de brincadeiras, o compartilhamento de suas estruturas básicas e o significado compartilhado em torno do tema da brincadeira. Esses estudos descreveram o início e a consolidação de brincadeiras em turmas de bebês em creches, concluindo que o compartilhamento da brincadeira só ocorre pela frequência das interações entre crianças nesse espaço.

Não foram localizados estudos que abordem de maneira etnográfica e longitudinal ${ }^{3}$ as diferentes formas de participação dos bebês em brincadeiras em contextos coletivos de educação e cuidado, como é a proposta do presente texto. Compreendemos que a inserção em uma comunidade de práticas, como uma instituição de Educação Infantil, possibilita a participação em um conjunto de atividades compartilhadas. Entre essas atividades, a brincadeira condensa as vivências das crianças do grupo e de outras gerações de crianças, transitando entre o universal e o particular, o individual e o coletivo, o contexto local e o contexto histórico-cultural mais amplo.

A pesquisa de campo busca analisar o processo de construção das brincadeiras e segue os princípios da Etnografia em Educação (CASTANHEIRA et al, 2001; GREEN; BLOOME, 1997). Tais princípios estão ligados à suspensão de categorias a priori e a uma descrição densa de aspectos da vida de um grupo em uma perspectiva holística e êmica, no sentido de relacionar cada aspecto com o contexto geral e enfatizar os significados que algo tem para o grupo (GREEN; DIXON; ZAHARLICK, 2005). Explicitamos, em particular para uma pesquisa com crianças, a noção de que os significados são expressos por meio de diferentes meios semióticos, como os símbolos, artefatos, roupas, ações, gestos, palavras, choros, sorrisos, olhares.

O acompanhamento etnográfico do grupo de bebês teve início em fevereiro de 2017 e continua até o presente momento, fevereiro de 2019. A EMEI Tupi é uma instituição pública de Educação Infantil em Belo Horizonte, Minas Gerais, e atende aproximadamente 400 crianças. As turmas do berçário e de 1 ano (Turma do Abraço) são atendidas em tempo integral. O grupo, em 2018, foi constituído por 9 meninas e 5 meninos (com idade entre 18 e 24 meses), uma professora-referência e uma professora de apoio em cada turno, além de uma

3 Um estudo semilongitudinal pioneiro no Brasil foi desenvolvido por Zilma Ramos de Oliveira, na década de 1980, na Universidade de São Paulo, orientado por Clotilde Rosseti-Ferreira. Ela acompanhou duas turmas de crianças de 2 e 3 anos, simultaneamente, durante 12 meses, e analisou formas de coordenação de papéis sociais no desenrolar das brincadeiras nesse período. 
auxiliar ao longo do dia. A professora-referência do turno vespertino, Verônica, acompanha a turma desde 2017.

O material empírico da pesquisa está sendo gerado por meio de filmagens do cotidiano do grupo, além do registro escrito em diário de campo. Em 2017, observamos $42 \%$ dos dias letivos da turma investigada (80 dias). Em 2018, até o mês de julho, foram acompanhados integralmente dois dias por semana do grupo, o que soma 33 dias de observação.

Selecionamos, para este texto, eventos que nos ajudassem a compreender melhor a unidade simbólica brincando de roda. Com base em Corsaro (1985) e Castanheira et al. (2001), conceituamos um evento como uma sequência de ações (com a presença ou não de outros bebês e adultos) em torno de um tema e/ ou objetivo específico. Um evento, nesse sentido, é um resultado dos processos vivenciados pelos participantes e é identificado analiticamente a posteriori ao reconhecermos seu começo, seu desenvolvimento e seu fim.

Os eventos foram selecionados com o propósito de situar a construção da brincadeira de roda no grupo e seu processo de transformação ao longo do período observado, focalizando como as crianças e professoras sustentam e participam. Nossa revisão bibliográfica aponta que a trajetória da brincadeira nas configurações de um grupo de crianças é algo que os estudos do brincar ainda não conseguiram mostrar empírica e teoricamente. De modo geral, esses estudos têm centralizado a relação entre brincadeira e aprendizagem escolar, e muito recentemente na América Latina, tentado evidenciar o seu valor cultural (FLEER, 2013). Uma leitura dialética da brincadeira, portanto, pode tornar visível o modo como as ações individuais e coletivas apoiam o desenvolvimento dessa atividade das crianças.

\section{A brincadeira como atividade-guia do desenvolvimento cultural do bebê}

A constatação de que há uma grande dificuldade em conceituar e distinguir brincar/brincadeira não é nova (KISHIMOTO, 2012). Uma das hipóteses que poderia justificar tal dificuldade é a de que a brincadeira não é um conceito clássico e, portanto, reside nessa premissa a ideia de que não haveria uma propriedade comum a todas as brincadeiras das crianças. Assim, a brincadeira constitui-se como uma categoria relacional sobre a qual incidem múltiplos elementos (comunidade, objetos, objetivos, participantes, papéis, cenários, motivos); logo, uma das dificuldades de conceitualização advém da ideia de que brincar/brincadeira 
expressa sempre uma ou mais relações em determinadas situações. Portanto, o brincar pode ser considerado uma ação na qual os múltiplos propósitos impactam na origem, no desenvolvimento e na caracterização da brincadeira.

Vigotski defende a importância de reconhecer como as necessidades das crianças se realizam na brincadeira, assim como as inclinações e os motivos relacionados a essa atividade. Para ele, "sem a compreensão das peculiaridades desses impulsos, não é possível imaginar que a brincadeira seja um tipo específico de atividade" (2008, p. 25). Segundo o autor bielorrusso, a brincadeira surge na primeira infância, quando emerge um conjunto de desejos irrealizáveis, coexistindo com uma tendência de satisfação imediata desses desejos, algo que se conserva na idade pré-escolar. Essa contradição entre o irrealizável e a necessidade de realização é resolvida pela criança por meio de substituições e resignações. O próprio autor destaca que não se trata de "desejos isolados, e sim, de afetos generalizados" (VIGOTSKI, 2008, p. 26), no sentido de que são externos aos objetos e se referem à vivência da brincadeira como um todo.

A motivação para brincar não é algo que existe dentro da criança individual, mas situa-se na relação com as outras pessoas e com o meio, sustentando-se no processo de participação nessa atividade, sendo cultural e coletivamente construída. Ela é uma atividade que surge de necessidades e relações sociais, mesmo em se tratando de bebês. Partimos do princípio de que a criação de uma situação imaginária é central na distinção da brincadeira no conjunto de outras atividades da criança. Nessa perspectiva, nem toda atividade da criança é brincadeira, que emerge quando o sentido é apropriado pela criança e desprende-se do objeto (VIGOTSKI, 2008). Se a criança brinca com os sentidos que o objeto adquire para ela e não com o objeto em si, logo, o fazer de conta é um processo de significação a partir do qual as crianças transformam o significado dos objetos e ações durante suas vivências em seu mundo social e material (VIGOTSKI, 2008), e se engajam com papéis e regras da vida cotidiana. Essa criação da situação imaginária permite um mover-se constante entre o real e o imaginado, o estar dentro e fora da brincadeira (FLEER, 2013).

A situação imaginária, assim, pode configurar a essência da brincadeira não só entre as crianças, uma vez que existe semelhança entre crianças e adultos em relação à gênese, função e estabilidade do faz de conta. Portanto, o faz de conta, a fantasia e a imaginação têm função na vida das pessoas de todas as idades e persistem na ontogênese humana (SCHOUSBOE, 2013). A persistência de brincadeiras tradicionais, em diferentes grupos geracionais, mostra como essa atividade tem um fim em si mesma e nos leva a fazer uma leitura da brincadeira no tempo presente, como o desenvolvimento contínuo do engajamento em práticas culturais que começa desde o nascimento e se transforma durante a vida. 
Ao identificarmos a situação imaginária e a considerarmos como unidade na compreensão da brincadeira, entendemos que ela contém as propriedades centrais da brincadeira ${ }^{4}$ : as identidades sociais (quem faz o que na brincadeira), as regras implícitas construídas localmente (quem pode fazer o que - funções, e de que maneira - ações) e os sentidos que a situação e os objetos assumem (o que cada coisa e ação representam). Trata-se de um processo de significação complexo no qual as questões do mundo, os interesses e as necessidades são vivenciados cognitiva e emocionalmente pelas crianças.

Pesquisar o processo de construção da brincadeira entre bebês constitui um campo de possibilidades para compreender, na ontogenia da criança, onde ela se retira do imediatismo das funções corporais e faz tentativas de explorar símbolos culturais compartilhados (WINTHER-LINDQVIST, 2013). O duplo posicionamento da criança no faz de conta entre as possibilidades reais e as necessidades internas faz com que ela construa representações simbólicas da vida cotidiana. Defendemos, então, que o faz de conta expressa uma unidade de análise das ações da criança na brincadeira, por meio das quais ela constrói conhecimentos sobre o mundo.

\section{A dupla temporalidade da brincadeira de roda}

Toda brincadeira tem história em um grupo social e, ao mesmo tempo, um campo de possibilidades que projeta o desenvolvimento da criança para outras temporalidades. Ao brincar de roda, as crianças expressam uma tradição cultural de muitas gerações e, simultaneamente, reinventam modos de brincar nas condições e contextos em que se encontram. A tradição oral e a transmissão cultural que engendram a construção dessa brincadeira coexistem com as reinvenções cotidianas de crianças que brincam juntas.

As brincadeiras de roda, em uma perspectiva socioantropológica, são tratadas como fenômenos culturais que possuem a função de perpetuar a cultura infantil e sustentar a convivência social (KISHIMOTO, 2012). Elas são consideradas patrimônios culturais transmitidos há muitas gerações e carregam algum grau de ritualização das ações, o que justifica a ênfase nas referências a brincadeiras tradicionais nos estudos de autores considerados folcloristas, como Fernandes (1979) e Cascudo (2006).

4A partir da argumentação de Winther-Lindqvist (2013) sobre a estrutura da brincadeira como unidade de análise, defendemos que o faz de conta é que expressa tal unidade, por considerar que ele designa a síntese do brincar e a menor estrutura de maior complexidade da construção da brincadeira. 
A brincadeira de roda constitui um tipo de jogo tradicional que faz parte da cultura popular e possui algumas características universais como anonimato, tradicionalidade, transmissão oral, conservação e mudança. A tensão entre conservação e mudança, particularidade e universalidade está presente em toda a literatura oral para crianças, incluindo as cantigas de roda que ganham versões diferentes em nosso país (KISHIMOTO, 2012). Assim, a permanência dessa prática com novas nuances só é possível porque adultos brincam com crianças e crianças brincam juntas, produzindo diferentes sentidos para a atividade de brincar de roda.

Autores como Opies e Opies começaram, em 1940, a gravar e catalogar brincadeiras, rimas e poesias infantis na Inglaterra. Esse trabalho é um marco na consideração daquilo que as crianças brincam, da linguagem que utilizam e das formas regionais que diversificam o repertório de brincadeiras e rimas infantis. No Brasil, o estudo sobre a formação de grupos de brinquedo no bairro Bom Retiro em São Paulo (FERNANDES, 1979) também desloca o foco da origem da brincadeira e empreende a tarefa de descrever e compreender como o grupo de brinquedos se forma, do que eles brincam e quais características marcam essa brincadeira. Fernandes chegou à definição de cantiga de roda como um tipo de folguedo simples. Sua estrutura, nesse sentido, é assegurada pelo grupo por meio de ações como dar as mãos, fazer a roda, girar e cantar, geralmente interrompida pelo final da música.

É, pois, interessante o deslocamento que essa tradição cultural operou na história, tanto do ponto de vista dos sujeitos que brincam, quanto da sua função social. De uma prática supostamente originada no universo adulto, hoje há uma associação dessa brincadeira às culturas da infância e uma centralidade nas instituições de Educação Infantil como um dos poucos lugares onde as crianças aprendem a brincar de roda. Há, dessa maneira, uma cultura infantil formada por elementos exclusivos desse grupo, já que mesmo sendo um elemento da cultura adulta, a cantiga de roda praticamente desapareceu entre os adultos e continua sendo recriada pelas crianças. A dupla temporalidade da brincadeira de roda, então, está, de um lado, no patrimônio cultural que acumula as construções de muitas gerações precedentes ao longo da história, e de outro, no fato de estar sempre impregnada pela significação que as crianças e adultos constroem no momento em que brincam juntos.

A tensão constante entre tradição e criação é central na compreensão dos modos de reprodução interpretativa dessa brincadeira pelas crianças. As culturas da infância e a reprodução interpretativa são categorias importantes para compreender o modo como as crianças participam de rotinas culturais que ajudam a compor a dinâmica do grupo. Nessa participação, as crianças estão atribuindo sentidos e construindo um repertório específico desse grupo que brinca junto 
(CORSARO, 2011). Em nosso trabalho, reconhecemos a dimensão histórica dessa prática cultural e centramos a análise no modo como essa prática começa e se transforma em um grupo de crianças, do berçário à turma de 1 ano, entre o primeiro semestre de 2017 e o primeiro de 2018.

Partindo do princípio de que a situação imaginária é fundante na construção do motivo para brincar, consideramos que, na roda, a situação imaginária começa a ser criada por meio das cantigas entoadas pelas crianças e professoras. $\mathrm{O}$ enredo imaginário criado pela cantiga engendra os movimentos corporais e sustentam os motivos e o prazer desencadeados pela brincadeira de roda, como analisaremos nos eventos seguintes.

\section{As brincadeiras de roda na Turma do Abraço}

No dia 2 de abril de 2018, fomos surpreendidas com o evento que inicia este texto: uma iniciativa de Simone $(23 \mathrm{~m} 2 \mathrm{~d})^{5}$ para propor, com ações e palavras, brincar de roda com outra criança. Nossa surpresa relacionou-se com o fato de uma criança com menos de dois anos de idade iniciar e sustentar uma prática tradicional com elementos culturais bem marcados em sua caracterização. Compreender como as crianças construíram oportunidades para brincar de roda e uma perspectiva compartilhada dessa brincadeira leva-nos a investigar os modos como as crianças aprendem e atualizam uma brincadeira tradicional no cotidiano do grupo. Assim, retomamos os registros etnográficos da pesquisa desde 2017, bem como entrevistamos a professora Verônica e a mãe de Simone.

Entre fevereiro e julho de 2017, observamos que as professoras cantaram algumas cantigas de roda, geralmente com apoio do dispositivo de som. A maioria dos bebês, nesse período, não andava e se locomovia engatinhando ou em pé, apoiando nas paredes e objetos. No dia 3 de agosto, primeiro evento com brincadeira de roda representado na figura 1, a professora Janete faz uma roda com bebês sentados e canta Borboletinha e Atirei o pau no gato. Janete está em pé, bate com as mãos na perna, sorri e olha atentamente para um dos bebês que também está em pé olhando para ela. Nesse evento, alguns bebês batem

5 A idade das crianças será apresentada em meses (m) e dias (d) em relação à data em que o evento ocorreu. Com isso, pretendemos enfatizar os processos de desenvolvimento biológico que marcam essa fase de crescimento dos bebês e que são integrados aos processos de desenvolvimento cultural. 
palmas sem balbuciarem. O evento dura dois minutos, momento em que os bebês começam a se deslocar em direção aos brinquedos que estão no chão da sala.

Já no dia 10 de agosto, a professora Ivana está sentada com os bebês e pega um chocalho em formato de boneco que está com um deles. Com o artefato, a professora faz movimentos de bater palmas, pular e rodar. Ela está sentada com Valéria ( $16 \mathrm{~m} 8 \mathrm{~d})$ no colo e parece se concentrar nesta bebê, que a olha e sorri. Ivana levanta-se e canta Alface já nasceu e enfatiza os movimentos de pular e rodar. Ela sorri e demonstra prazer em brincar com os bebês. Alguns deles a olham e balançam a cabeça. Henrique (12m 14d) levanta-se e faz movimentos

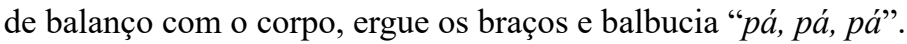

As formas que essa prática assume no grupo nesses momentos acompanham as possibilidades de deslocamento dos bebês. Contudo, a ação da professora, ao se posicionar em pé, gesticulando e cantando, amplia essas possibilidades para alguns bebês que começam a se levantar e se movimentar pela sala. Alguns bebês olham e imitam a ação de bater palmas. A imitação, nesse sentido, é considerada um processo volitivo, no qual há uma escolha da criança em imitar os adultos ou outras crianças, no intuito de fazer algo que não consegue realizar sozinha, e engendra possibilidades de desenvolvimento (VIGOTSKI, 1997).

FIGURA 1 - EVENTOS DE BRINCADEIRA DE RODANA TURMA - AGOSTO/2017 A JULHO/2018

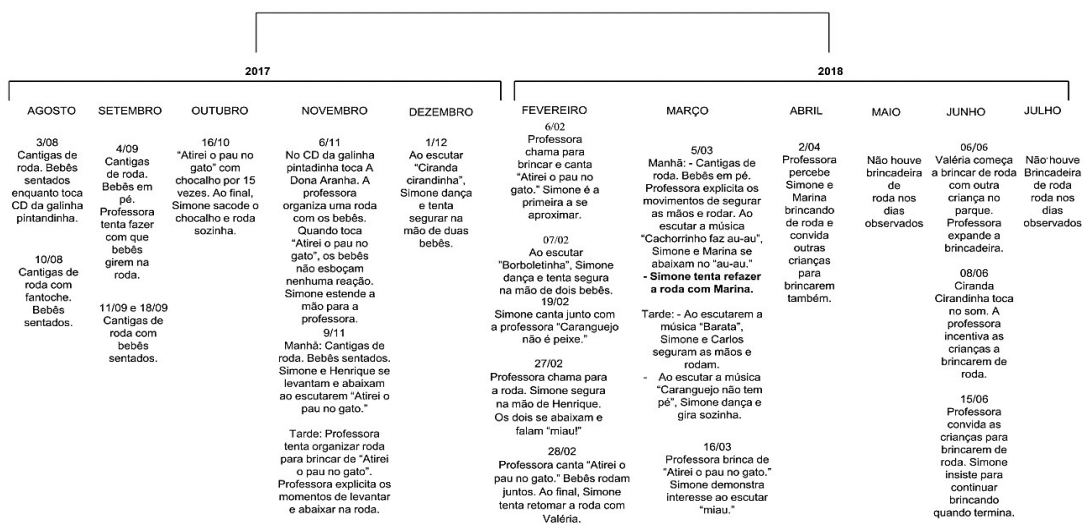

FONTE: Banco de dados da pesquisa. Elaboração das autoras, 2018. 
Essa rotina cultural aos poucos se modifica. Por exemplo, no dia 4 de setembro de 2017, alguns bebês estão sentados em uma almofada grande, em formato de minhocão, da sala, há duas bebês na piscina de bolinhas e a professora Lorena começa a cantar Caranguejo não é peixe. A professora bate os pés no chão e bate palmas. Simone $(17 \mathrm{~m})$ e Lúcia $(15 \mathrm{~m} 5 \mathrm{~d})$ olham na direção da professora que começa a cantar. Simone bate palmas e a professora a retira da piscina para cantar junto ao grupo que está sentado. A professora diz "deixa eu ver se Simone sabe" e canta "palma/ palma/ palma/ pél pél $p e ́ "$. Simone repete os gestos de bater palmas e os pés. A professora Lorena repete o mesmo trecho direcionando-se à Larissa $(14 \mathrm{~m} 25 \mathrm{~d})$, que está em pé, dizendo "e a Larissa, sabe?". Larissa aproxima-se de Simone e a observa, enquanto Simone canta junto à professora os finais da cantiga "pél pél pé". Simone roda a mão ao escutar "roda/ roda/ roda" e ao final da cantiga diz " $\hat{e} / \hat{e} / \hat{e}$ " (batendo palmas). Os outros bebês participam do evento olhando atentamente, enquanto Lúcia continua na piscina de bolinhas olhando para o grupo e balançando o corpo. Ao perceber o interesse de Lúcia, Lorena retira-a da piscina e diz que vai colocar uma música para dançar. Ela canta o mesmo trecho da cantiga uma vez mais, perguntando se Lúcia sabe fazer. Nessa última cantiga, Simone, Henrique e Larissa batem palmas e os pés, enquanto Lúcia observa a professora.

A professora reconhece o interesse de Simone e a importância de sua participação na brincadeira, que até aquele momento não se configurava na estrutura de roda. Com a inserção de Simone, a brincadeira complexifica-se e cria possibilidades de desenvolvimento para todo o grupo, que observa atentamente sua construção. Há a introdução dos movimentos de bater o pé e tentar girar as mãos, em concomitância com o reconhecimento das palavras pé e roda, e começam a emergir as regras da brincadeira de roda: é necessário fazer determinados gestos acompanhando a letra da cantiga. A seguir, a professora liga o som, convida todos para brincarem de roda em pé, segura na mão de Larissa, que desiste da roda. Simone e Henrique se aproximam, levantam as mãos e a professora faz a roda com eles. Mesmo com a troca de músicas e a professora dizendo "acabou", os dois mantêm o interesse na roda, erguendo os braços na direção da professora.

O evento do dia 16 de outubro evidencia o trabalho intencional da professora Ivana em função da aprendizagem da roda pelos bebês. Ela começa cantando Atirei o pau no gato enquanto sacode um chocalho. Inicialmente, ela marca as pausas da cantiga, enfatizando o barulho feito pelo artefato chocalho. Ao perceber que Henrique ( $17 \mathrm{~m} 12 \mathrm{~d}$ ) se aproxima e dança, ela deixa o chocalho e segura na sua mão. A seguir, Ivana segura na mão de Valéria (16m 14d) e canta outra vez. Simone ( $17 \mathrm{~m}$ 5d) aproxima-se e leva as mãos na direção da 
professora, que reafirma um importante elemento desse tipo de brincadeira: segurar na mão do colega. Os outros bebês continuam brincando com artefatos pela sala, mas olham para a roda. Alguns dançam e batem o pé. Ivana chama a atenção dos bebês para agacharem no miau, sentando-se no chão ao dizer "olha/ o miau é assim". Simone e Henrique se agacham. A brincadeira é repetida 15 vezes ao longo de nove minutos. Em pé, sentados, a cada execução, há inserção de outros bebês, que sacodem chocalhos, batem palmas, batem bolinhas uma na outra ou apenas olham. Ao final, Simone pega o chocalho e fica rodando sozinha. Em seguida, a professora canta uma música mais calma e os bebês se sentam próximos a ela.

Salientamos a extensão temporal que marca esse evento, nove minutos, em contraste com os dois minutos que marcaram a primeira roda de agosto. Tal extensão torna visível o crescente interesse do grupo por essa brincadeira, assim como a participação destacada de Simone. Como no dia 4 de setembro, a formação da roda é iniciada por Henrique. O balançar do seu corpo é interpretado pela professora como um convite para segurar as mãos e formar uma roda. Há, portanto, um processo de produção compartilhada dos sentidos e significados que a roda começa a ter para os bebês e professoras, que ativamente se engajam em uma brincadeira tradicional da nossa herança cultural.

Em síntese, a brincadeira de roda é inserida na turma ainda no berçário, com a audição das cantigas copiladas em uma produção cultural brasileira de ampla difusão, a Galinha Pintadinha. Observamos ações das professoras de cantar junto aos bebês e cantar em momentos em que eles estão sentados explorando objetos. Paulatinamente, os movimentos corporais são incentivados pelas professoras, uma vez que fundamentam a composição estética da roda, de acordo com as regras culturais dessa brincadeira: ficar em pé, dar as mãos e rodar. Trata-se de uma prática educativa, apoiada em uma herança cultural, em torno do ensinar a brincar de roda. A introdução de elementos da roda pelas professoras não segue, necessariamente, uma progressão linear em relação ao desenvolvimento dos bebês, mas impulsionam esse desenvolvimento. Por meio de ações corporais expressivas e intencionais (olhar, bater palmas, balançar, levantar, balbuciar, apontar, erguer as mãos), os bebês produzem sentidos e significados compartilhados com as professoras, como o de ficar em pé e segurar nas mãos como fundantes para a participação na brincadeira de roda, que foram se fortalecendo em 2018, como analisaremos a seguir. 


\section{Evento Vamos brincar de miau?}

A participação de Simone nas brincadeiras de roda começou a chamar nossa atenção pelo fato de que, em 2018, observamos tentativas de iniciar a brincadeira sem o envolvimento direto de nenhum adulto. Selecionamos dois eventos com o objetivo de compreender o engajamento dessa criança nessa rotina cultural. Em 5 de março, a tarde inicia-se com uma sequência de brincadeiras de roda em que a professora Eliza canta "Abre a roda/ tindolele" e convida as crianças para "fazer a roda". Ela ajuda as crianças a darem as mãos e rodar. A brincadeira de roda acontece na sequência de três músicas que tocam no CD da Galinha Pintadinha. Pouco tempo depois, no evento Vamos brincar de miau? (FIGURA 2), Simone (22m 1d) segura as mãos de Marina (22m 27d) e de Bento $(23 \mathrm{~m} \mathrm{11d})$ e ficam olhando para a professora durante alguns segundos. Ela parece esperar que a professora retome a roda que acontecia antes com a turma. As professoras Silvana e Eliza não percebem o interesse da criança e, então, Simone puxa Marina e Bento para o fundo da sala.

\section{FIGURA 2 - SEQUÊNCIA DO EVENTO VAMOS BRINCAR DE MIAU?}
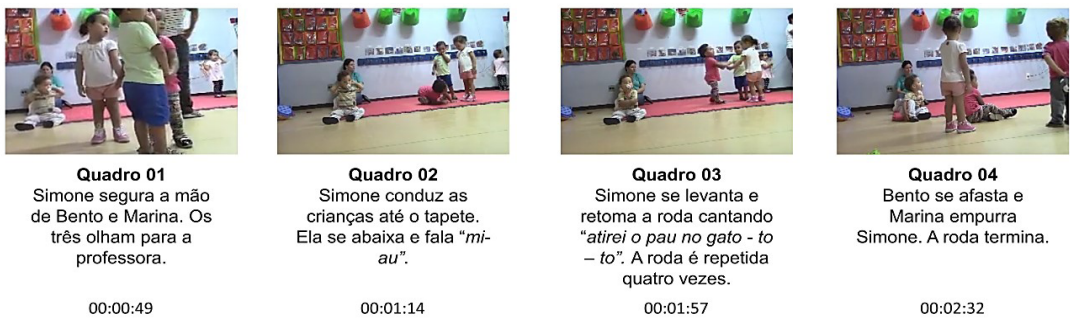

FONTE: Banco de dados da pesquisa. Elaboração das autoras, 2018.

Como esse evento foi construído ao longo do tempo nessa turma? Ao analisarmos a participação de Simone em outros eventos de roda, percebemos várias ações: ela aproximou-se da professora, cantando, batendo palmas, segurou a mão da professora ou de alguma criança. São pistas comunicativas do seu interesse na brincadeira de roda (FIGURA 3). Para iniciar essa brincadeira, que é coletiva, percebemos que as estratégias de comunicação adotadas por Simone, em 05/03/2018, foram importantes. Quando ela se abaixa e diz miau, Marina e Bento a observam e, em seguida, dão as mãos e rodam juntos, demonstrando aceitar o convite. A onomatopeia miau constitui-se como parte significante da 
cadeia de significação da brincadeira, produzindo sentidos e significados compartilhados em uma rotina cultural daquele grupo.

FIGURA 3 - PARTICIPAÇÃO DE SIMONE NAS BRINCADEIRAS DE RODA NA TURMA, 2018

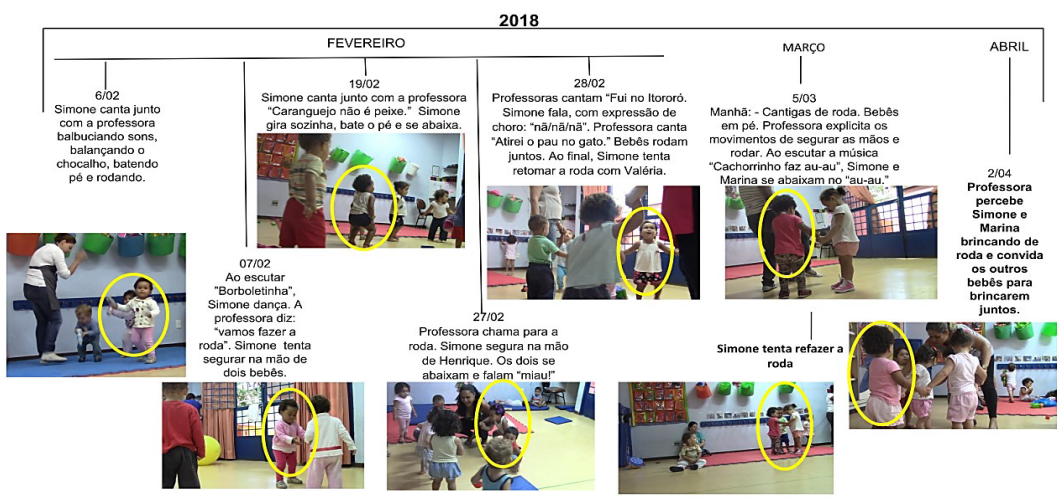

FONTE: Banco de dados da pesquisa. Elaboração das autoras, 2018.

Compreendemos que o compartilhamento é fundamental para a participação em brincadeiras coletivas como a roda. Corsaro (2011) analisa esse elemento como ethos da infância, algo central nas atividades que envolvem expressões padronizadas, repetitivas e cooperativas, como é o caso da repetição do miau na brincadeira de roda Atirei o pau no gato. A produção de um significado compartilhado, no entanto, é desafiadora para bebês e crianças muito pequenas. $\mathrm{O}$ processo de construção da brincadeira de roda na turma indica que a participação nas suas mais diversificadas formas e lógicas de construção da brincadeira é importante. Entretanto, a construção da roda em si encontra muitos desafios que precisam ser solucionados pelas crianças: quedas, puxões do braço, rupturas na configuração estética, conflitos e negação do parceiro.

As tentativas de brincar de roda nesses eventos mostram que há algo nessa brincadeira que provoca prazer nas crianças. A repetição do gesto de agachar, da onomatopeia miau, o movimento de rodar, segurar nas mãos das outras crianças ou simplesmente brincar junto confirmam que a natureza predominante da brincadeira é brincar com outras pessoas (SUTTON-SMITH, 1986). Portanto, compartilhamento, participação, parceria e amizade são construções que acontecem nas brincadeiras coletivas e que começam muito cedo, entre os bebês que 
compartilham rotinas diárias em contextos coletivos de cuidado e educação. Em nossa investigação, um mês após a primeira brincadeira de roda iniciada por Simone, constatamos que Marina repete essas ações gestuais e verbais para indicar a brincadeira, como analisaremos na próxima seção.

\section{Evento Simone enlaça crianças e professora}

Após algumas tentativas de pegar água sobre a pia, Simone anda em direção ao fundo da sala. É uma sala ampla e a professora está terminando de contar uma história no tapete. As crianças já começam a se dispersar e a professora as convida para brincar com os brinquedos. Simone aproximase da professora e de Marina, tenta pegar sua mão. Marina não entende o gesto, puxa a mão e começa a chorar. A professora faz um carinho na mão de Marina e diz à Simone que precisa fazer carinho. Simone repete o gesto de carinho na mão de Marina e em seguida segura sua mão e se afasta da professora. Marina também segura a mão de Larissa e as três caminham de mãos dadas para o lado oposto da sala. Ao caminhar, Simone balbucia dançando: nã-nã-nã-nã. Marina se abaixa e diz: miau. Parece, nesse momento, que Marina comunica a intenção de brincar de atirei o pau no gato. No tapete, a professora "brinca de abraçar" com Lúcia, mas observa o movimento das meninas. Ao ver a porta da sala aberta, Marina foge e as demais esperam de mãos dadas. O retorno de Marina muda a configuração da roda, pois Valéria entra no lugar de Larissa. Simone, Marina e Valéria fazem a primeira roda cantando Atirei o pau no gato com todas as estruturas que compõem a cantiga de início, meio e fim. A professora Verônica aproxima-se e comenta: "olha pessoal!! que legal!/ vai Valéria/ canta/ atirei o pau no gato-to-to". A professora amplia a brincadeira, incentivando a entrada de outras crianças na roda. A brincadeira de roda, após a participação da professora, é repetida outras três vezes mesmo com a entrada e saída de crianças. Algumas crianças cantam, mas todas seguram na mão, rodam e se abaixam ao final (Vídeo gravação, 2 de abril de 2018).

Esse é o evento com o qual introduzimos o texto e que evidencia um nível de compartilhamento de alguns princípios desse tipo de brincadeira. Isso só foi possível porque, ao participarem de outras brincadeiras de roda juntos desde o berçário, os bebês apropriam-se da forma estética, da linguagem e do próprio repertório de cantigas. Outro ponto importante é a estabilidade na parceria entre 
Simone e Marina nas duas rodas que acontecem por iniciativa das crianças, algo que permanece na trajetória das duas meninas na turma.

Com a participação da professora, o evento dura ainda outros dois minutos e as crianças retomam a roda diversas vezes, com novos participantes. Nesse caso, vimos que todas as crianças participam da brincadeira de alguma forma, havendo inclusive sub-rodas com duas ou três crianças. No total, esse evento dura cinco minutos, tempo superior ao evento descrito no mês de março, em que as professoras não percebem a roda das crianças. Para Verônica, sua participação permite "uma sequência na brincadeira/ a retomada cada vez que eles abaixam no miau e soltam as mãos/além da mediação dos conflitos que surgem quando alguém não quer segurar as mãos" (Entrevista em 06/06/2018).

A estrutura de participação nos dois eventos é semelhante: as crianças fazem gestos de abaixar, dizendo miau, de segurar na mão do colega e balançar o corpo. Essa estrutura enfatiza as habilidades comunicativas, verbal e não verbal, necessárias à participação na brincadeira, e evidencia um compartilhamento do significado do gesto de agachar e dizer miau como indicativo da cantiga de roda. A ritualização da roda, ao conservar elementos estéticos, permite também a sua retomada pelas crianças desde muito pequenas. A professora Verônica, ao comentar a presença da brincadeira de roda na turma e o interesse das crianças, destaca: "não tenho dúvida de que eles aprenderam brincar de roda aqui com a gente/ com as outras crianças/ que outro lugar/ hojel crianças da idade deles brincam de roda? / em casa a maioria nem tem irmãos" (Entrevista, 06/06/2018). A percepção da professora dialoga com o que diz a mãe de Simone: "ela certamente aprendeu brincar de roda aqui (na EMEI)". Como brincadeira coletiva, de fato, a roda pressupõe, no mínimo, que haja outra criança para brincar, e, desse modo, a inserção em um grupo estável na Educação Infantil configura-se como um espaço privilegiado para brincar de roda na contemporaneidade.

Vale ressaltar que a construção de um contexto de brincadeira, nessa turma, é subsidiada pela disposição de espaços-tempos nos quais as crianças podem escolher o que fazer e pelo contato com produções culturais para as crianças. Ao longo de 2018, há uma maior compreensão do significado da brincadeira por um maior número de crianças, especificamente a percepção da necessidade do parceiro e da manutenção do enlaçamento das mãos. As professoras também desenvolvem um olhar diferenciado para a prática que ganha espaço no grupo, participando e expandindo a atividade. Enquanto adultas mais experientes que entram e saem da brincadeira, elas aumentam sua complexidade e apoiam a relação entre a imaginação individual e coletiva (FLEER, 2013), colaboram para o compartilhamento do significado que a brincadeira vai assumindo no grupo. 


\section{Considerações finais}

Os eventos de brincadeiras de roda em um grupo de crianças entre 12 e 26 meses de idade questionam argumentos que enfatizam a primazia da brincadeira individual e com objetos nesse grupo etário. $\mathrm{O}$ interesse das crianças por uma brincadeira coletiva que envolve algum grau de ritualização e contornos estéticos específicos levaram-nos a suspender juízos a priori sobre o que constitui a brincadeira entre bebês. No berçário, a inserção do CD Galinha Pintadinha, a iniciativa das professoras de cantarem enquanto os bebês estavam sentados e ampliarem as possibilidades de movimento e narrativa musical nos momentos em que os bebês começaram a dançar marcaram as primeiras experiências de construção da brincadeira de roda. Um dos padrões nessas práticas é a cooperação entre professoras e bebês, fundada na atenção às pistas de interesse destes.

Além do acesso a uma narrativa imaginária, as ações e falas das crianças (como a de imitar o gato miando e caindo ao final da brincadeira) atuam como símbolos para representar simbolicamente o animal ausente e fazem a função de mediadores semióticos. O fazer de conta que um gato fez um miau forte ao levar uma paulada da Dona Chica acompanha a movimentação corporal das crianças e a metacomunicação durante a brincadeira. Nesse sentido, brincar de roda nesse grupo pode ser considerada uma atividade revolucionária ${ }^{6}$, pois deriva de uma situação imaginária, cria regras a partir dela, sustenta uma prática coletiva e cria um significado que sintetiza a relação entre as condições reais e a imaginação.

As vivências dos bebês ao longo do tempo foram fundamentais para a construção da brincadeira de roda e, simultaneamente, essas brincadeiras fortaleceram as relações entre as crianças. Os eventos analisados demonstram a potencialidade de considerar aquilo que acontece quando os bebês e crianças pequenas estão juntos como central para a compreensão do que as proposições curriculares da área querem demarcar com a centralidade das interações e das brincadeiras. As professoras, ao perceberem que essa brincadeira se tornou uma prática cultural, uma vez que passou da apreciação pelos bebês a uma atividade regulada por suas ações, assumiram a tarefa de ensinar a brincar de roda.

A participação dos bebês em uma herança cultural como a brincadeira de roda ajuda-nos a compreender as dinâmicas de construção coletiva e individual das oportunidades de brincar no grupo, evidenciando que mesmo que a iniciativa

6 Esse termo é utilizado por Newman e Holzman (2014) em Lev Vygotsky, cientista revolucionário, para se referirem à criação de uma situação imaginária pela criança como criação de significado. 
seja de um bebê ou da professora, todo o grupo se desenvolve. Fazer a roda com ajuda da professora e brincar de roda com ajuda de bebês que comunicam explicitamente a intenção de brincar são atividades que representam desafios àquilo que os bebês podem fazer sozinhos. Como atividade social, a brincadeira de roda acontece entre pessoas e pressupõe uma rede de relações que se fortalece e a torna mais complexa. Assim, trata-se de um trabalho intencional de criação de possibilidades de desenvolvimento coletivo.

A análise do processo de construção da brincadeira de roda revela a potência das atitudes das professoras quando estas apoiam, acolhem e ampliam as experiências das crianças. Isso só foi possível em uma dinâmica de observação e escuta sensível e, sobretudo, do reconhecimento de que algo importante acontece no encontro entre elas desde muito pequenas. Essas relações e práticas constituem o currículo vivenciado pela turma e não podem ser invisibilizadas em nome de uma lista de conteúdos e habilidades previamente estabelecidas.

\section{REFERÊNCIAS}

BORBA, Ângela. Culturas da infância nos espaços-tempos do brincar. Tese de doutorado. Universidade Federal Fluminense, 2005.

CASCUDO, Luís da Câmara. Literatura oral no Brasil. São Paulo: Global, 2006.

CASTANHEIRA, Maria L., CRAWFORD, Tereza, DIXON, Carol, e GREEN, Judith. Interactional ethnography: An approach to studying the social construction of literate practices. In: CUMMING, Joy e WYATT-SMITH, Clayre (Eds.). Special issue of Linguistics and Education: Analyzing the Discourse Demands of the Curriculum, 11 (4), 2001, p. 353-400.

CORSARO, William A. Friendship and peer culture in the early years. Norwood, N.J.: Ablex. 1985.

CORSARO, William A. Sociologia da Infância. 2 ed. Tradução: Lia Gabriele Regius Reis. Porto Alegre: Artmed, 2011.

COUTINHO, Ângela M. S. A acção social dos bebês: um estudo etnográfico no contexto da creche. Tese de doutorado. Universidade do Minho, Portugal, 2010.

ERICKSON, Frederick; SCHULTZ, Jeffrey. "O quando" de um contexto: questões e métodos na análise da competência social. In: RIBEIRO, Bianca T.; GARCEZ, Pedro M. Sociolinguística interacional. São Paulo: Loyola, 2002, p. 215-234. 
FERNANDES, Florestan. As ‘trocinhas' do Bom Retiro: contribuição ao estudo folclórico e sociológico das culturas e grupos infantis. In: . Folclore e mudança social na cidade de São Paulo. 2. ed. Rio de Janeiro: Vozes, 1979, p. 153-258.

FLEER, Marilyn. Collective Imagining in Play. In: SCHOUSBOE, Ivy; WINTHERLINDQVIST, Ditte. Children's Play and Development: Cultural-Historical Perspectives. New York: Springer International Handbooks of Education, 2013, p. 73-88.

GREEN, Judith; BLOOME, David. Ethnography and ethnographers of and in education: a situated perspective. In: FLOOD, James; HEATH, Shirley; LAPP, Diane. (Eds.). A handbook of research on teaching literacy through the communicative and visual arts. New York: Simon \& Shuster Macmillan, 1997, p. 181-202.

GREEN, Judith L.; DIXON, Carol N.; ZAHARLICK, Amy. A etnografia como uma lógica de investigação. Tradução de Adail Sebastião Rodrigues Júnior e Maria Lúcia Castanheira. Educação em Revista: Belo Horizonte, v. 42, p.13-79. Dez 2005. Disponível em: www. scielo.br/scielo.php?script=scinlinks\&ref=000168\&pid=S0102. Acesso em: 10 out. 2017.

KISHIMOTO, Tizuko Morchida. Jogos infantis: o jogo, a criança e a educação. 17 ed. Petrópolis, RJ: Vozes, 2012.

LORDELO, Eulina; CARVALHO, Ana Maria. Padrões de parceria social e brincadeiras em ambientes de creches. Psicologia em Estudo, Maringá, v. 11, n. 1, p. 99-108, jan./abr. 2006. Disponível em: http://www.scielo.br/scielo.php?script=sci_arttext\&pid. Acesso em: 12 abr. 2017.

MUSSATI, Tulia; PANNI, S. Social behavior e interaction among day care center toddlers. Early child development and care, 7, 5-27, 1981. Disponível em: https://www.tandfonline. com/doi/abs/10.1080/0300443810070102. Acesso em: 03 jul. 2018.

NEWMAN, Fred. HOLZMAN, Lois. Lev Vygotsky, cientista revolucionário. 2 ed. Tradução de Marcos Bagno. São Paulo: Loyola, 2014.

PEDROSA, Maria Isabel; CARVALHO, Ana Maria. A interação social e a construção da brincadeira. Cadernos de Pesquisa, São Paulo, n 93, p. 60-65, 1995. Disponível em: http:// publicacoes.fcc.org.br/ojs/index.php/cp/article/view/849/856. Acesso em: 10 jun. 2018.

PRADO, Patrícia. Educação e cultura infantil em creche: um estudo sobre as brincadeiras de crianças pequenininhas em um CEMEI de Campinas/ SP. Dissertação de Mestrado, Universidade Estadual de Campinas, Campinas, 1998.

REX, L.; GREEN, J.; DIXON, C. What Counts When Context Counts? The Uncommon "Common" Language of Literacy Research. Journal of Literacy Research, v. 30, n. 3, p. 405-433, 1998. Disponível em: http://journals.sagepub.com/10.1080/10. Acesso em: 05 mai. 2018.

SCHOUSBOE, Ivy. The Persistence of Play and what if thinking. In: SCHOUSBOE, Ivy; WINTHER-LINDQVIST, Ditte. Children's Play and Development: Cultural-Historical Perspectives. New York: Springer International Handbooks of Education, 2013, p. 197-214. 
STAMBACK, Mira; VERBA, Mina. Organization of social play among toddlers: an ecological approach. In: MUELLER, Edward; COOPER, Catherine. Process and outcome in peer relationships. New York: Academic Press, 1986, p. 114-134.

SUTTON-SMITH, B. Toys as culture. New York: Gardner Press, 1986.

VIGOTSKI, Lev. S. Obras Escogidas, IV. Psicología Infantil. Madrid: Visor Distribuciones, 1997. Texto original escrito em 1934.

VIGOTSKI, Lev. S. A brincadeira e o seu papel no desenvolvimento psíquico da criança. Palestra proferida em 1933. Tradução de Zoia Prestes. Revista Virtual de Gestão de Iniciativas Sociais, n. 11, p. 23-36, jun. 2008. Disponível em: http://www.ltds.ufrj.br/ gis/anteriores/rvgis11.pdf. Acesso em: 20 mar. 2018.

WINTHER-LINDQVIST, Ditte. Playing with social identities: play in the everyday life of a peer group in Day Care. In: SCHOUSBOE, Ivy; WINTHER-LINDQVIST, Ditte. Children's Play and Development: Cultural-Historical Perspectives. New York: Springer International Handbooks of Education, 2013, p. 29-54.

Texto recebido em 11 de fevereiro de 2019.

Texto aprovado em 07 de julho de 2019. 